\title{
Hacia una inserción laboral juvenil efectiva en la RACS
}

\section{Roberto Fonseca Consultor}

Las estadísticas oficiales, derivadas de las Encuestas de Medición del Nivel de Vida (EMNV) y de las Encuestas Continuas de Hogares, indican que hay un número creciente de adolescentes y de jóvenes, del Caribe nicaragüense, entre los quince y veintinueve años de edad, que se ha incorporado al mercado laboral, reduciéndose paulatinamente la tasa de desempleo abierta en el periodo 2001-2009.

Sin embargo, otros estudios no gubernamentales de más reciente data, han profundizado sobre las características del mercado laboral juvenil en el Caribe nicaragüense y han confirmado que hay una serie de factores objetivos y subjetivos que impiden la incorporación plena y satisfactoria de adolescentes y jóvenes caribeños al empleo remunerado, obligándolos entonces a incursionar en trabajos precarios.

Esta insastifacción laboral entre adolescentes y jóvenes de las regiones autónomas, también se refleja en los resultados de grupos focales desarrollados por los autores de la investigación titulada "Estudio del mercado laboral juvenil en cinco municipios de la RACS", promovido por el Programa Educación para el Éxito, que impulsa la Fundación para la Autonomía y el Desarrollo de la Costa Atlántica de Nicaragua (FADCANIC).

\section{Radiografía del mundo laboral juvenil}

La población en edad de trabajar (PET), refiriéndose a la población mayor de catorce años en las regiones autónomas del Caribe nicaragüense (RACN y RACS), aumentó en 77,782, al pasar de 146,229 personas a 224,011 personas en el periodo 2001 a 2009, de acuerdo a resultados extraidos y procesados de las Encuestas de Medición del Nivel del Vida (EMNV), elaboradas por el Instituto Nacional de Información para el Desarrollo (antes INEC).

En 2009, de las 224,011 personas en edad de trabajar, el 56,7\% se ubicó en la categoria de población económicamente activa (PEA), entendiendo como tal, al conjunto de personas que están ocupadas, más las que buscan activamente un trabajo.
Mientras 43,2\% se ubicó en la categoría de la población económicamente inactiva (PEI), es decir, aquellas personas que, aunque estando en edad de trabajar, no laboraban en la semana de referencia en que se realizó la encuesta, ni buscaron trabajo durante las últimas cuatro semanas. Estas personas comúnmente son estudiantes, amas de casas, discapacitados permanentes, jubilados, etcétera.

\section{Gráfico 1 • Tendencias del PET, PEA y PEI en la Macro Región Caribe, 2001-2009}

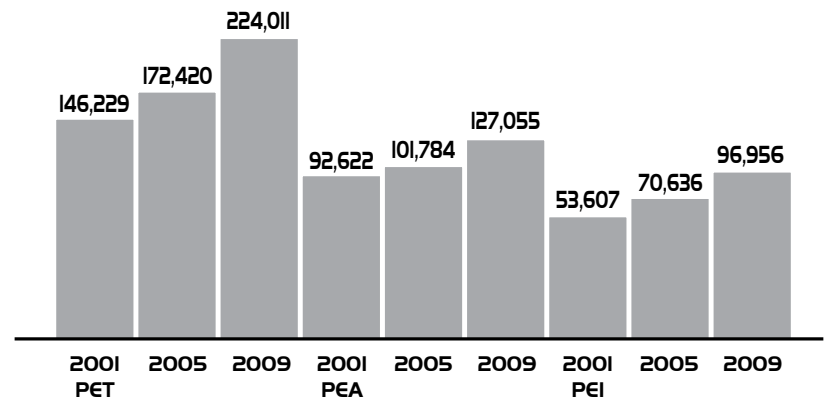

Fuente:Elaboración propia con datos de las Encuestas de Medición de Nivel de Vida (EMNV) de 2001, 2005 y 2009 realizadas por el Instituto Nicaragüense de Información para el Desarrollo (INIDE).

Este aumento de la población apta para laborar no representa una diferencia significativa con respecto a la media nacional, sin embargo comprende un desafío de mediano y de largo plazo dadas las características demográficas de las regiones autónomas, donde más de un tercio de la población total es joven (de trece a veintinueve años), teniendo las regiones autónomas, junto con Matagalpa y Jinotega, la mayor proporción de población menor de trece años. En el Caribe representan más del $40 \%$ de la población total. (Gráfico 2)

Según estimaciones del Programa de Naciones Unidas para el Desarrollo ${ }^{1}$, para el año 2020 las regiones autónomas serán de las regiones del país (junto con Río San Juan y Jinotega), que presentarán la composición de población 


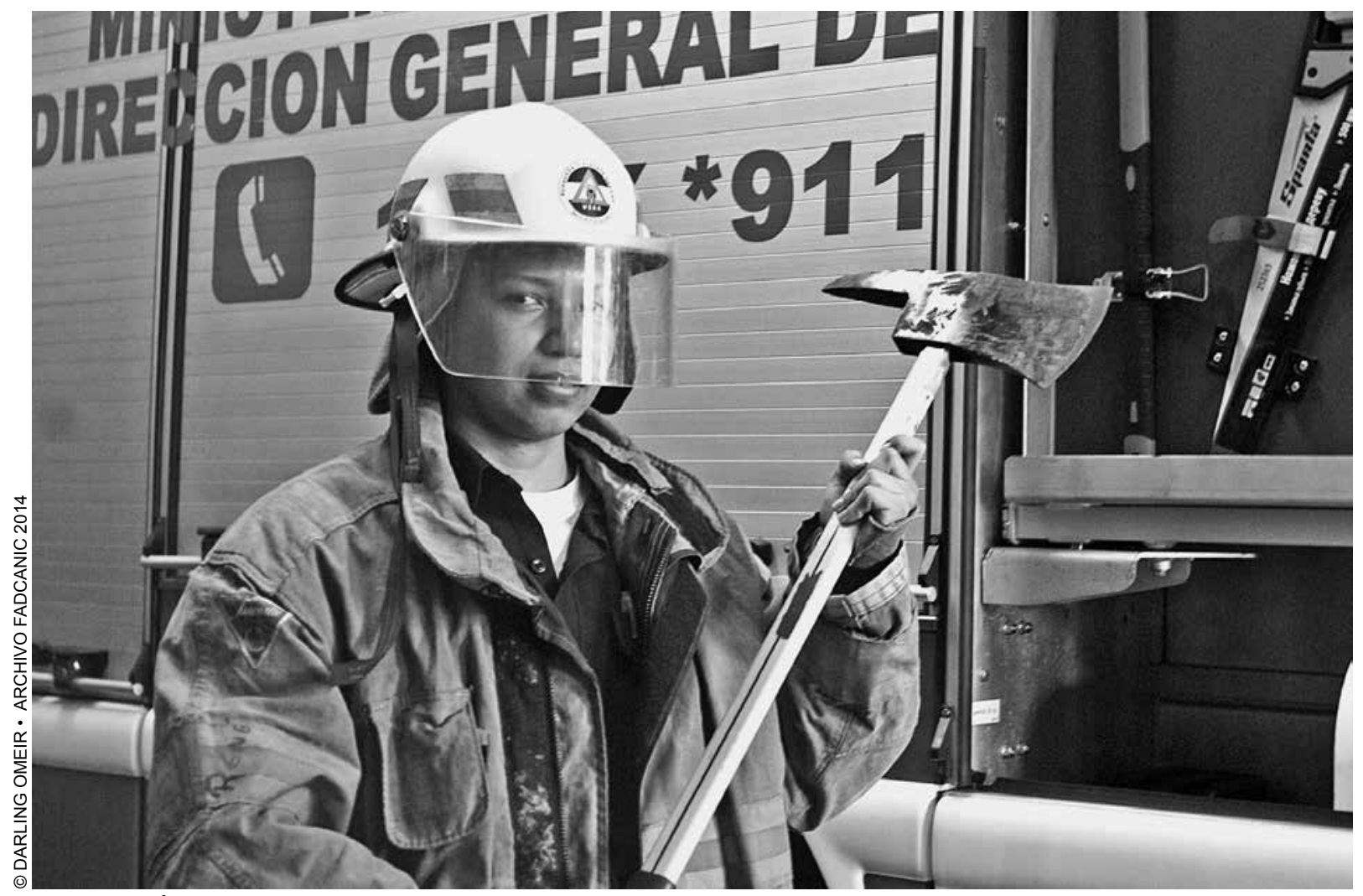

Carlos Jirón, veinte años, del cuerpo de bomberos de Bluefields.

más joven de Nicaragua, existiendo por tanto un mayor porcentaje de personas jóvenes interesadas en incorporarse al mundo laboral y desarrollar así sus capacidades productivas y profesionales.

A nivel nacional, entre el grupo poblacional entre dieciséis a veintinueve años, la tasa de ocupación ha mejorado del $86.8 \%$ al $90.7 \%$, según los indicadores del mercado laboral que se desprenden de las EMNV correspondientes a los años 2001, 2005 y 2009. (Tabla 1)

A esta mejoría no han escapado las regiones autónomas del Caribe nicaragüense, de acuerdo a los mismas cifras oficiales, ya que la tasa de ocupación mejoró del $88.4 \%$ al 97.2\%.

Por otra parte, la tasa de desempleo abierto en las regiones autónomas disminuyó de $11.5 \%$ al $2.75 \%$, en el mismo periodo de 2001 - 2009. Aunque la tasa de participación económica (que corresponde a la división entre PEA y PET) disminuyó en casi siete puntos porcentuales en el mismo periodo.

Sin embargo, pese a que esas cifras oficiales arrojan una mejoría porcentual, más de la mitad de los pobladores de las regiones autónomas (entre 54\% a 59\%), identifican el desempleo como su principal problema socioeconómico, de acuerdo a los resultados del estudio titulado "Sostenibilidzad institucional y socioeconómica de la Autonomía de la Costa Caribe", realizado por Antonio Aranibar y Francisco Canedo. Le sigue en orden de importancia la pobreza, con valores mucho menores, entre $17 \%$.

\section{Gráfico 2 • Composición etaria de la población según macroregiones (en porcentajes)}

$\square$ I2 años $\square$ I3-17 años $\square$ I8-29 años $\square 30$ años

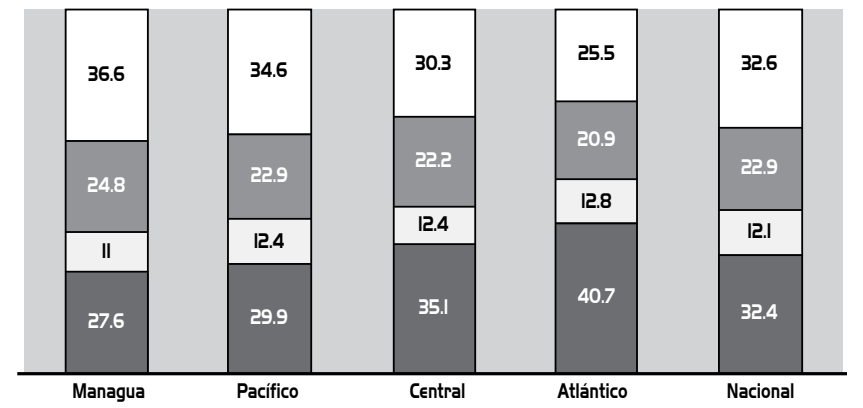

Fuente: IDH Nicaragua con base en el Censo de Población y Vivienda 2005 de INIDE. 
Tabla 1. Indicadores del mercado laboral por macro región (\%)

\begin{tabular}{lccccccccc}
\hline \multirow{2}{*}{$\begin{array}{l}\text { Regiones } \\
\text { Macroeconómicas }\end{array}$} & \multicolumn{3}{c}{ Tasa de Ocupación } & \multicolumn{3}{c}{ Tasa de Desempleo Abierto } & \multicolumn{3}{c}{$\begin{array}{c}\text { Tasa de Participación } \\
\text { Económica }\end{array}$} \\
\cline { 2 - 11 } & $\mathbf{2 0 0 1}$ & $\mathbf{2 0 0 5}$ & $\mathbf{2 0 0 9}$ & $\mathbf{2 0 0 1}$ & $\mathbf{2 0 0 5}$ & $\mathbf{2 0 0 9}$ & $\mathbf{2 0 0 1}$ & $\mathbf{2 0 0 5}$ & $\mathbf{2 0 0 9}$ \\
\hline Managua & 81.68 & 86.92 & 85.58 & 18.32 & 13.08 & 14.42 & 62.08 & 63.71 & 57.61 \\
\hline Pacifico & 87.39 & 92.00 & 88.42 & 12.61 & 8.00 & 11.58 & 62.80 & 61.41 & 57.87 \\
\hline Centro Norte & 90.14 & 95.83 & 94.18 & 9.86 & 4.17 & 5.82 & 63.89 & 61.25 & 58.52 \\
\hline Atlántico & 88.46 & 97.42 & 97.25 & 11.54 & 2.58 & 2.75 & 63.34 & 59.03 & 56.72 \\
\hline Total & $\mathbf{8 6 . 8 2}$ & $\mathbf{9 2 . 4 1}$ & $\mathbf{9 0 . 7 3}$ & $\mathbf{1 3 . 1 8}$ & $\mathbf{7 . 5 9}$ & $\mathbf{9 . 2 7}$ & $\mathbf{6 2 . 9 9}$ & $\mathbf{6 1 . 6 8}$ & $\mathbf{5 7 . 8 5}$ \\
\hline
\end{tabular}

Fuente: Elaboración propia con datos de las Encuestas de Medición de Nivel de Vida (EMNV) de 2001,2005 y 2009 realizadas por el Instituto Nicaragüense de Información para el Desarrollo (INIDE).

Esta preocupación por el desempleo coincide con los resultados que se desprenden de las entrevistas y los grupos focales realizados en los municipios de Bluefields, Laguna de Perlas, Kukra Hill, Corn Island y La Desembocadura del Río Grande, donde FADCANIC desarrolla el Programa Educación para el Éxito, en los cuales participaron actores económicos-productivos, autoridades regionales y municipales, autoridades del sector educativo y, finalmente, los propios jóvenes caribeños organizados y no organizados. A continuación, dos de estos comentarios:

Son pocos los empleos de calidad y en su mayoría se encuentran en la alcaldía y en las áreas de gerencia de las empresas pesqueras y estos cargos son cedidos a personas mayores con años de experiencia. (Empresario Privado-Sector Pesca)

En la actualidad el tipo de empleo existente es temporal mayoritariamente. Solo los empleados de las instituciones gubernamentales se pueden considerar estables y se benefician de las prestaciones. (Profesora de Secundaria)

\section{Contexto económico y productivo del Caribe nicaragüense}

Según el Informe de desarrollo humano 2005: las regiones autónomas de la Costa Caribe; ¿Nicaragua asume su diversidad? del PNUD, la economía de las regiones autónomas de la costa Caribe de Nicaragua se desarrolla bajo tres modos de producción:

- Economía campesina
- Economía indígena y étnica comunitaria y

- Economía empresarial exportadora de materias primas a nivel primario. (PNUD, 2005, p. 155)

Según el mismo informe, estos modos de producción se articulan y gestan en contextos espaciales diversos, de forma dinámica, con involucramiento de diferentes actores sociales. Para efectos de análisis y caracterización, el informe propone cuatro zonas productivas:

- Zona marino-costera; habitada por 44 comunidades, de las cuales 18 pertenecen a la RACN y 26 a la RACS; en esta última se incluyen los municipios de Laguna de Perlas, Bluefields, La Desembocadura del Rio Grande, Corn Island y El Rama.

- Zona de sabanas de pino, conocida como zona de los llanos; ubicada sobre una llanura de 488.611 hectáreas, de las cuales el 97 por ciento está en la RACN y el 3 por ciento en la RACS.

- Zona de bosque húmedo tropical; la RACN dispone de 1.9 millones de hectáreas de bosque húmedo tropical; las principales áreas, además de las protegidas, se ubican entre el río Coco, río Waspuk y sobre el eje vial RositaBilwi y, más al sur, entre los ríos Bambana y Akawas.

Por su parte, la RACS posee 1,6 millones de hectáreas, en las cuales se incluyen sus áreas protegidas, la mayor parte ubicadas en dos direcciones, la primera sobre la franja paralela a la costa y la segunda que colinda con el departamento de Río San Juan. Existen dos actividades económicas importantes en la zona: la forestal, bosques, y la minera en el subsuelo del bosque. 


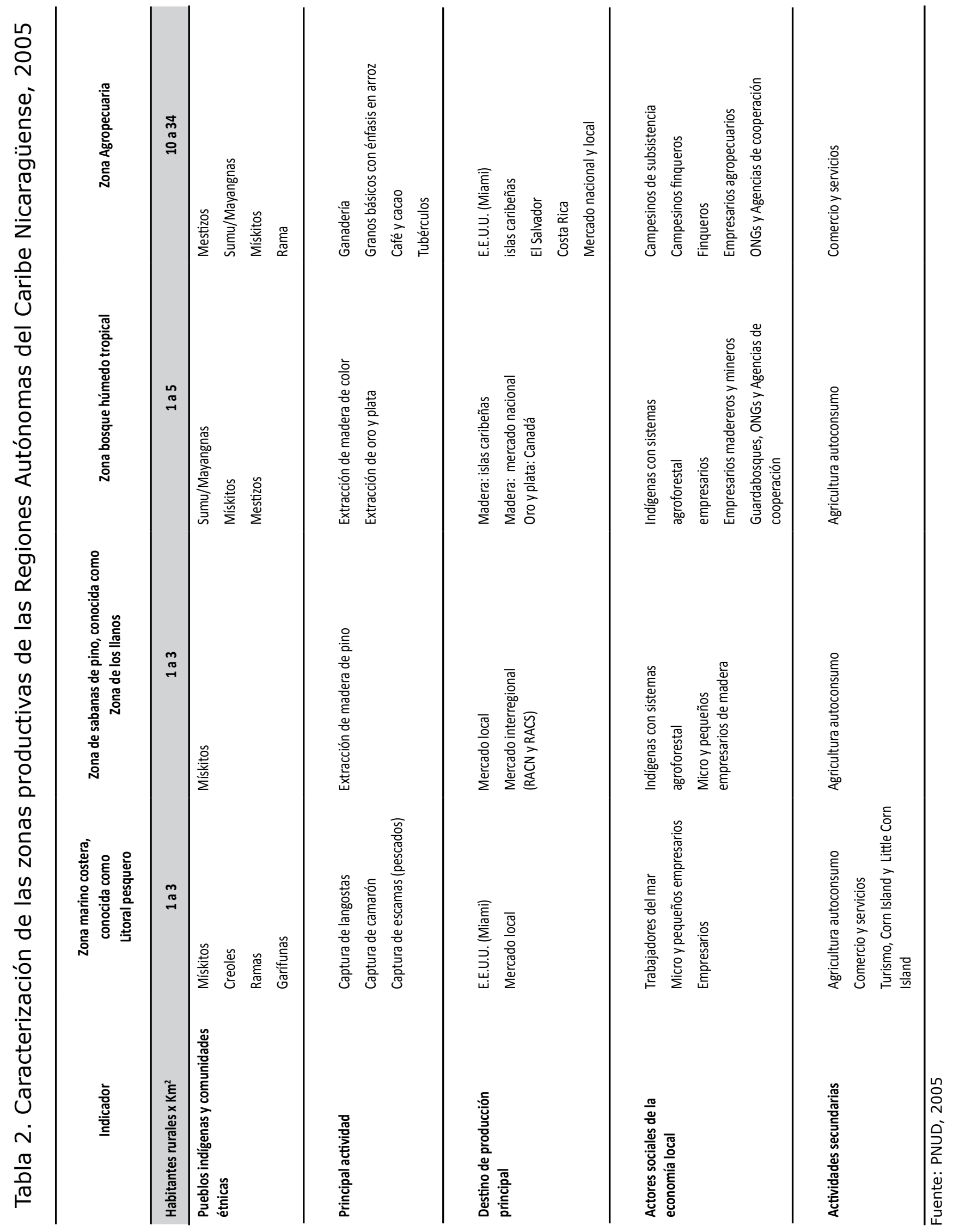


- Zona agropecuaria; en la zona, de acuerdo a los patrones de comportamiento de los sistemas productivos, se distinguen cuatro subzonas: la ganadera; la de agricultura diversificada con sistemas de cultivos intensivos; la subzona agropecuaria de subsistencia mestiza; y la subzona agroforestal indígena.

Un resumen de los principales indicadores que caracterizan a estas zonas productivas se presenta en la Tabla 2. Cuatro de los municipios donde se desarrolla el programa de FADCANIC (La Desembocadura, Laguna de Perlas, Bluefields y Corn Island), se ubican en la zona marino-costera y uno (Kukra Hill), se ubica en la zona agropecuaria. En la Tabla 3, se presentan las principales actividades productivas de los municipios de interés de esta investigación.

En base a los sectores productivos y potencialidades de las regiones autónomas, el gobierno de Nicaragua formuló el Plan de Desarrollo Humano para las regiones autónomas (GRUN, 2007), con participación de los consejos y de los gobiernos regionales de la RACN y la RACS. En dicho plan se diagnosticó el estado de aquellos sectores que resultan primordiales para dinamizar la economía regional y procurar medios de acceso a bienes materiales para la población costeña. Los sectores económicos priorizados son: la agro-industria, pesca, turismo y desarrollo forestal.

La actividad económica por medio de la cual los hogares obtienen sus ingresos diarios también es un indicador importante que aporta evidencia para caracterizar los sectores de ocupación de la población. De acuerdo a los
Tabla 3. Principales actividades productivas de cinco municipios costeros de la RACS

\begin{tabular}{ll}
\hline Municipio & Principales Actividades Productivas \\
\hline Bluefields & $\begin{array}{l}\text { Procesamiento de productos } \\
\text { pesqueros, pesca industrial y } \\
\text { artesanal, agricultura. }\end{array}$ \\
Corn Island & $\begin{array}{l}\text { Procesamiento de productos pes- } \\
\text { queros, pesca industrial } \\
\text { y artesanal }\end{array}$ \\
Desembocadura & Pesca y agricultura \\
Kukra Hill & Agricultura y agroindustrias \\
Laguna de Perlas & Pesca y agricultura \\
\hline
\end{tabular}

Fuente: Williamson Cuthbert 2007

resultados recopilados por la "Encuesta sobre diversidad, pertenencia, identidad y los regímenes de autonomía municipal y regional" realizada por el CASC-UCA/IPADE en 2004, las principales actividades económicas son la pesca, la agricultura y el comercio, entre otras.

Como es posible observar, la gráfica presenta un mapa claro sobre las principales ocupaciones/actividades productivas que generan ingresos por comunidad étnica y pueblo indígena; teniendo un peso relevante, la pesca, seguida de la siembra y el comercio. En menor proporción: la ganadería, la minería y las artesanías.

Tabla 4. Principales fuentes de ingreso por grupos étnicos en las Regiones Autónomas Norte y Sur del Caribe nicaragüense (en porcentajes)

\begin{tabular}{|c|c|c|c|c|c|c|}
\hline Fuentes de Ingreso & Mestiza & Mískito & Sumu Mayangna & Negro Creole & Rama & Garífuna \\
\hline Artesanías & 0 & 2 & 0 & 1 & 0 & 0 \\
\hline Comercio & 16 & 10 & 3 & 10 & 0 & 5 \\
\hline Ganadería & 9 & 3 & 6 & 0 & 0 & 2 \\
\hline Minería & 0 & 0 & 1 & 0 & 0 & 0 \\
\hline Pesca & 2 & 10 & 0 & 35 & 63 & 55 \\
\hline Remesas & 2 & 3 & 0 & 8 & 0 & 2 \\
\hline Servicios & 31 & 15 & 9 & 19 & 4 & 0 \\
\hline Siembra & 28 & 48 & 27 & 3 & 31 & 22 \\
\hline Otras & 10 & 10 & 50 & 24 & 2 & 15 \\
\hline
\end{tabular}

Fuente: CASC-UCA/IPADE, 2004. Encuesta sobre diversidad, pertenencia, identidad y los regímenes de autonomía municipal y regional. 


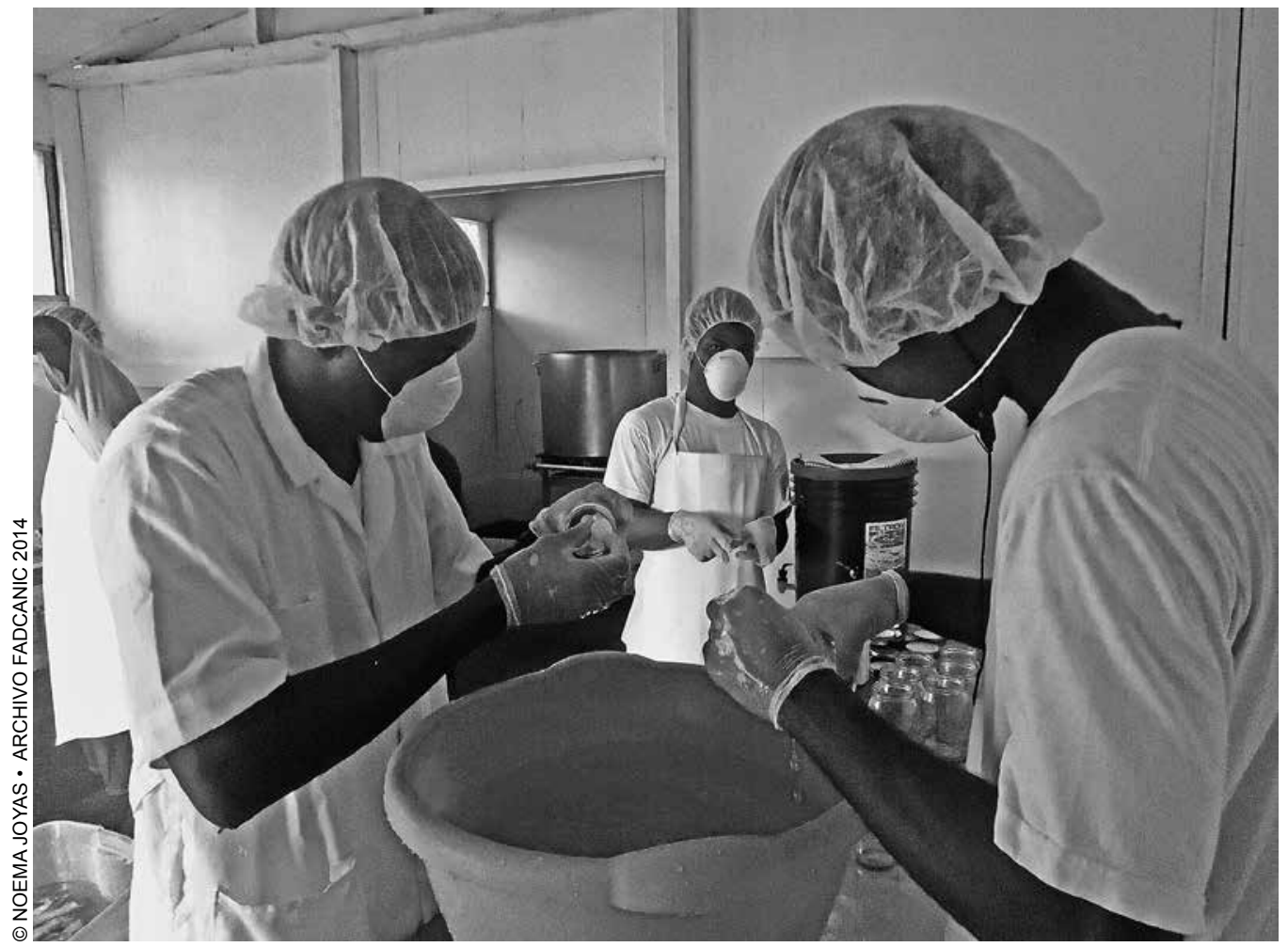

Curso de procesamiento y envasamiento de alimentos.

\section{Profundizando en el mercado laboral}

Las estadísticas que se derivan de los instrumentos oficiales del INIDE confirman los hallazgos anteriores, ya que casi siete de cada diez pobladores del Caribe nicaragüense se dedica ahora a las actividades relacionadas a la agricultura y la ganadería, seguida del comercio.

Mientras las cifras confirman también que se va reduciendo el peso de la pesca, va aumentando el trabajo doméstico y cobrando relevancia la población dedicada al magisterio o la enseñanza.

La distribución de la población ocupada por rama de actividad concentra a la población principalmente en actividades económicas primarias (actividades desarrolladas en los sectores de agricultura, ganadería, silvicultura y pesca) que requieren una baja o casi nula formación técnica-profesional y cuyos salarios/ingresos suelen estar basados en la capacidad de producción de cada trabajador.

En segundo lugar, la población ocupada está vinculada a actividades secundarias relacionadas con los sectores de explotación de minas y canteras, industria manufacturera y construcción; y en último lugar, actividades económicas terciarias (actividades desarrolladas en los sectores de electricidad y agua, transporte y comunicaciones, establecimientos financieros, servicios comunales, sociales y personales), coincidiendo esta caracterización con el perfil productivo y modos de producción vigentes en las regiones autónomas.

Las actividades agropecuarias y la pesca, con características estacionales, son las mayores generadoras de empleos, que de acuerdo a los resultados de los grupos focales resultan ser trabajos temporales, mal remunerados, sin beneficios sociales y laborales, y copados por adultos. Las opiniones entre jóvenes, autoridades locales y hasta actores económicos en los cinco municipios de la RACS antes mencionados, confirman estas percepciones.

\footnotetext{
"En el municipio, la dinámica laboral es estacionaria principalmente en los sectores más productivos en la actualidad (pesca y turismo), y en menor medida, la agricultura y el comercio".

"En Pearl Lagoon, los sectores que generan ingresos son muy pocos, está la pesca, la agricultura y ahora el que más genera es el turismo”.
} 
"En Kukra, la empresa Cukra Development Corporation representa el mayor motor laboral. Las principales empresas que brindan oportunidad de trabajo son la palma africana, Nica Bambú, y La Cacao, estas empresas se encuentran en el sector productivo de nivel primario".

“En La Desembocadura, los entrevistados mencionaron que la principal actividad económica que (se) desarrolla en el Municipio es la pesca, seguidamente la agricultura y de ultimo están los servicios y actividades vinculadas a jornalearía, aserrado y asalariados".

"Los sectores productivos son limitados y en su mayoría ya están saturados o son estacionarios, lo que no permite estabilidad laboral”.
En la Tabla 6, puede observarse el nivel de especialización/ formación de la población ocupada en la región. Es interesante observar que en el periodo 2001-2009 ha aumentado la incorporación de obreros calificados, lo que podría reflejar un avance de las opciones técnicas, sin embargo, el porcentaje sigue siendo poco relevante. Esa misma tendencia positiva se observa en la cantidad de técnicos básicos y medios, que están incorporados al empleo remunerado en el Caribe nicaragüense. Sin embargo, lo que resulta contradictorio es el peso preponderante de los empleados con nivel dirigencial.

Al respecto, una participante del grupo focal de Laguna de Perlas ilustra: "Yo apliqué siete veces a diferentes opciones de trabajo al salir de la Universidad; fue a la octava aplicación que me otorgaron un puesto de trabajo. El salario era el mínimo, pero agradezco [...] la oportunidad otorgada, porque ahora tengo la experiencia que tanto se exige".

Tabla 5. Distribución de la Población Ocupada de las regiones autónomas norte y sur del Caribe nicaragüense, según Actividad Económica

\begin{tabular}{|c|c|c|c|c|c|c|}
\hline \multirow{2}{*}{ Rama de Actividad Económica } & \multicolumn{2}{|c|}{2001} & \multicolumn{2}{|c|}{2005} & \multicolumn{2}{|c|}{2009} \\
\hline & Cantidad & $\%$ & Cantidad & $\%$ & Cantidad & $\%$ \\
\hline Agricultura y ganadería & 41,639 & 50.82 & 61160 & 61.68 & 81313 & 65.8 \\
\hline Pesca & 2,695 & 3.29 & 3688 & 3.72 & 1816 & 1.47 \\
\hline Minas y canteras & 2,693 & 3.29 & 897 & 0.9 & 189 & 0.15 \\
\hline Industria manufacturera & 3,628 & 4.43 & 4038 & 4.07 & 2441 & 1.98 \\
\hline Electricidad, gas y agua & 203 & 0.25 & 25 & 0.03 & 266 & 0.22 \\
\hline Construcción & 4,095 & 5 & 3083 & 3.11 & 3004 & 2.43 \\
\hline Comercio & 9,781 & 11.94 & 9264 & 9.34 & 10006 & 8.1 \\
\hline Hoteles y restaurantes & 2,145 & 2.62 & 1570 & 1.58 & 2666 & 2.16 \\
\hline $\begin{array}{l}\text { Transporte, almacenamiento y } \\
\text { comunicaciones }\end{array}$ & 2,077 & 2.53 & 2671 & 2.69 & 3016 & 2.44 \\
\hline Intermediación financiera & 300 & 0.37 & 347 & 0.35 & 789 & 0.64 \\
\hline Administración pública y defensa & 2,246 & 2.74 & 2778 & 2.8 & 2417 & 1.96 \\
\hline Enseñanza & 2,512 & 3.07 & 5296 & 5.34 & 5894 & 4.77 \\
\hline Servicios sociales y de salud & 1,309 & 1.6 & 587 & 0.59 & 1781 & 1.44 \\
\hline $\begin{array}{l}\text { Servicios comunitarios, sociales y } \\
\text { personales }\end{array}$ & 2,755 & 3.36 & 1492 & 1.5 & 3509 & 2.84 \\
\hline $\begin{array}{l}\text { Hogares privados con servicio } \\
\text { domestico }\end{array}$ & 3,855 & 4.71 & 2059 & 2.08 & 4460 & 3.61 \\
\hline $\begin{array}{l}\text { Organizaciones y órganos } \\
\text { extraterritoriales }\end{array}$ & - & - & 204 & 0.21 & - & - \\
\hline
\end{tabular}

Fuente: Elaboración propia con datos de las Encuestas de Medición de Nivel de Vida (EMNV) de 2001, 2005 y 2009 realizadas por el Instituto Nicaragüense de Información para el Desarrollo (INIDE). 
Tabla 6. Distribución de la Población Ocupada de las regiones autónomas norte y sur del Caribe nicaragüense, según grupos ocupacionales

\begin{tabular}{|c|c|c|c|c|c|c|}
\hline \multirow{2}{*}{ Grupo Ocupacional } & \multicolumn{2}{|c|}{2001} & \multicolumn{2}{|c|}{2005} & \multicolumn{2}{|c|}{2009} \\
\hline & Cantidad & $\%$ & Cantidad & $\%$ & Cantidad & $\%$ \\
\hline Obrero no Calificado & 518 & 0.63 & 391 & 0.39 & 844 & 0.68 \\
\hline Obrero Calificado & 607 & 0.74 & 1,125 & 1.13 & 2,776 & 2.25 \\
\hline Servicios & 3,286 & 4.01 & 6,198 & 6.25 & 6,504 & 5.26 \\
\hline $\begin{array}{l}\text { Administradores, Técnicos } \\
\text { Básicos y Técnico Medio }\end{array}$ & 20,279 & 24.75 & 25,071 & 25.28 & 32,738 & 26.49 \\
\hline Técnico Superior y Profesionales & 9,797 & 11.96 & 8,493 & 8.57 & 3,496 & 2.83 \\
\hline Dirigentes & 47,446 & 57.91 & 57,881 & 58.37 & 77,209 & 62.48 \\
\hline
\end{tabular}

Tabla 7. Distribución de la Población Ocupada de las regiones autónomas norte y sur del Caribe nicaragüense, según categoría ocupacional

\begin{tabular}{lcccccc}
\hline & \multicolumn{2}{c}{2001} & & 2005 & & 2009 \\
Categoría Ocupacional & Cantidad & $\%$ & Cantidad & $\%$ & Cantidad & $\%$ \\
\hline $\begin{array}{l}\text { Empleado / obrero } \\
\text { Jornalero / peón }\end{array}$ & 27,606 & 33.69 & 25,530 & 25.8 & 28,223 & 22.84 \\
Cuenta propia & 10,757 & 13.13 & 15,124 & 15.3 & 23,717 & 19.19 \\
$\begin{array}{l}\text { Patrón o empresario } \\
\text { Trabajador sin pago o familiar }\end{array}$ & 12,949 & 15.8 & 18,633 & 18.8 & 21,321 & 17.25 \\
no remunerado & 28,601 & 2.47 & 1,698 & 1.7 & 1,013 & 0.82 \\
Trabajador no familiar sin pago & & 34.91 & 38,174 & 38.5 & 48,493 & 39.24 \\
\hline
\end{tabular}

Fuentes: Ambas Tablas son de elaboración propia con datos de las Encuestas de Medición de Nivel de Vida (EMNV) de 2001, 2005 y 2009 realizadas por el Instituto Nicaragüense de Información para el Desarrollo (INIDE). 


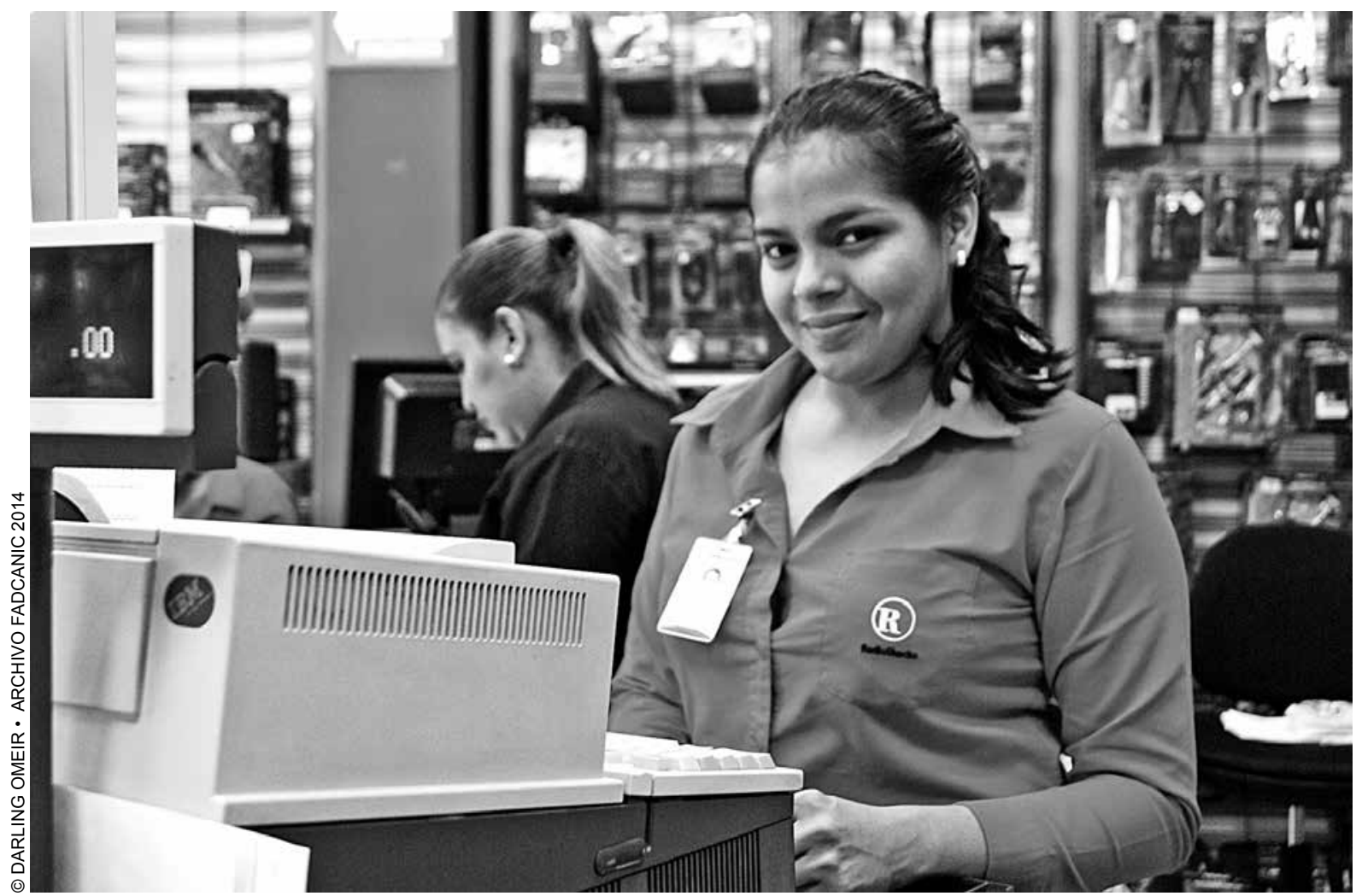

Sheverlee Fletes, de veinticuatro años, cajera.

Otro participante en los grupos focales organizados en los cinco municipios de la RACS, dijo lo siguiente: "En el municipio existe un pobre mercado laboral, que paga un salario mínimo y que no cumple con otorgar las prestaciones laborales que dicta la Ley".

En la Tabla 7, en términos de categorías ocupacionales (funciones que desempeña/ubicación jerárquica), la mayoría de la población laboral del Caribe nicaragüense se concentra en la categoría de empleado/ obrero ${ }^{4}$, seguido de "trabajador sin pago" o "trabajador familiar no remunerado", categoría que ha experimentado un aumento sustancial entre 2001 y 2009. Este último evidencia la incorporación de adolescentes y jóvenes como apoyo familiar, sin recibir salario, ni cobertura de seguridad social.

En el Censo Nacional Agropecuario 2011, elaborado por INIDE con asesoría internacional, se indica que en la RACS se contabiliza un total de 22,714 productores, de los cuales, $99,7 \%$ corresponde a productores individuales $(22,656)$.

Entre ese universo de productores individuales $(22,656)$, un total de 3,721 son varones, entre los dieciséis a treinta y cuatro años, mientras 754 son mujeres, en los mismos rangos de edad.
Según un representante de SEREJUVE/GRACS: "Para determinar la dinámica laboral en el municipio, es necesario hacer una clasificación entre sectores urbanos y rurales, pues en los sectores rurales el principal motor de trabajo gira alrededor de la agricultura, mientras que en el sector urbano está en torno al comercio".

\section{EI mundo laboral en la RACS desde la perspectiva juvenil}

La Encuesta Nacional de Adolescentes y Jóvenes (ENAJ), realizada y divulgada por el Programa de Naciones Unidas para el Desarrollo (PNUD), en el marco del IV Informe Nacional de Desarrollo Humano, titulado "Las Juventudes construyendo Nicaragua", profundizó sobre las características del mundo laboral juvenil en la RACS, determinando por ejemplo que sólo cuatro de cada diez jóvenes en la región estaban incorporados al mundo laboral.

En efecto, al momento de la encuesta, el 59\% de los encuestados refirió no haber tenido trabajo, es decir, no haber iniciado su vida laboral. Entre el $41 \%$ restante, que sí refirieron haber tenido trabajo, aseguraron que lo iniciaron principalmente en negocios o empresas vinculadas al comercio (34.5\%); seguido de empresas o negocios agropecuarios (19.8\%), actividades relacionadas al campo de la construcción (7.6\%), la pesca (7.1\%) y el servicio doméstico (7.1\%). 

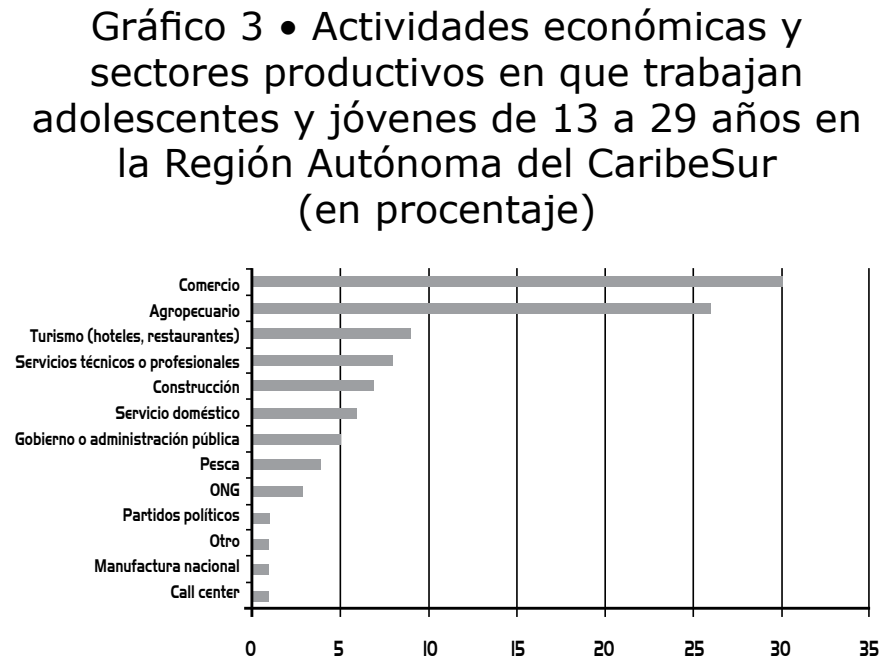

Fuente: Elaboración propia con datos de las Encuesta Nacional de Aspiraciones Juveniles realizada por PNUD en 2009.

Del universo laboral juvenil, el 24.8\% de los adolescentes y jóvenes tuvo su primera experiencia laboral entre los trece y dieciocho años. Por otra parte, el $73.7 \%$ ingresó al mundo laboral como asalariado; experimentando el $69.6 \%$ de ellos un periodo de búsqueda de trabajo, de uno atres meses. El 55\% del total de jóvenes que iniciaron su vida laboral refirió no haber estudiado mientras trabajaba.

Del total de jóvenes que inició su vida laboral, el 54.4\% lo hizo por elección, el $43.9 \%$ por necesidad y un $1,8 \%$ porque fue forzado a hacerlo.
El $71.4 \%$ de adolescentes y jóvenes consultados sobre su motivación a la búsqueda de trabajo, expresó que lo hizo con el objetivo de cubrir sus propios gastos, confirmando el $27.3 \%$ que su familia experimentaba una necesidad económica muy grave. Ambos porcentajes hacen referencia a las posibles situaciones que obligan al o a la adolescente $o$ joven a abandonar sus estudios para dedicarse a actividades productivas y generadoras de ingresos; constituyendo, esta situación, una dinámica de inserción laboral inefectiva y con riesgo de precariedad.

Esa valoración sobre la calidad del empleo se manifiesta en la percepción de uno de los jóvenes consultados en los grupos focales, sobre la necesidad de ingresar al mercado laboral: "Existe volatilidad del empleo [...] y la necesidad de encontrar un trabajo para buscar la sobrevivencia”. Ese sentido de urgencia obliga a tomar un empleo, incluso en condiciones precarias.

La principal modalidad de obtención del primer empleo, fue a través de amigos (40.9\%) seguido por la familia (29.2\%) y una búsqueda personal directa (19.3\%). Estas rutas de búsqueda, pueden ser un indicador de la importancia que posee disponer de capital social (relaciones sociales basadas en la confianza, la cooperación y la reciprocidad), (Weller, 2007: 76) para lograr tener mayores oportunidades de una inserción laboral exitosa.

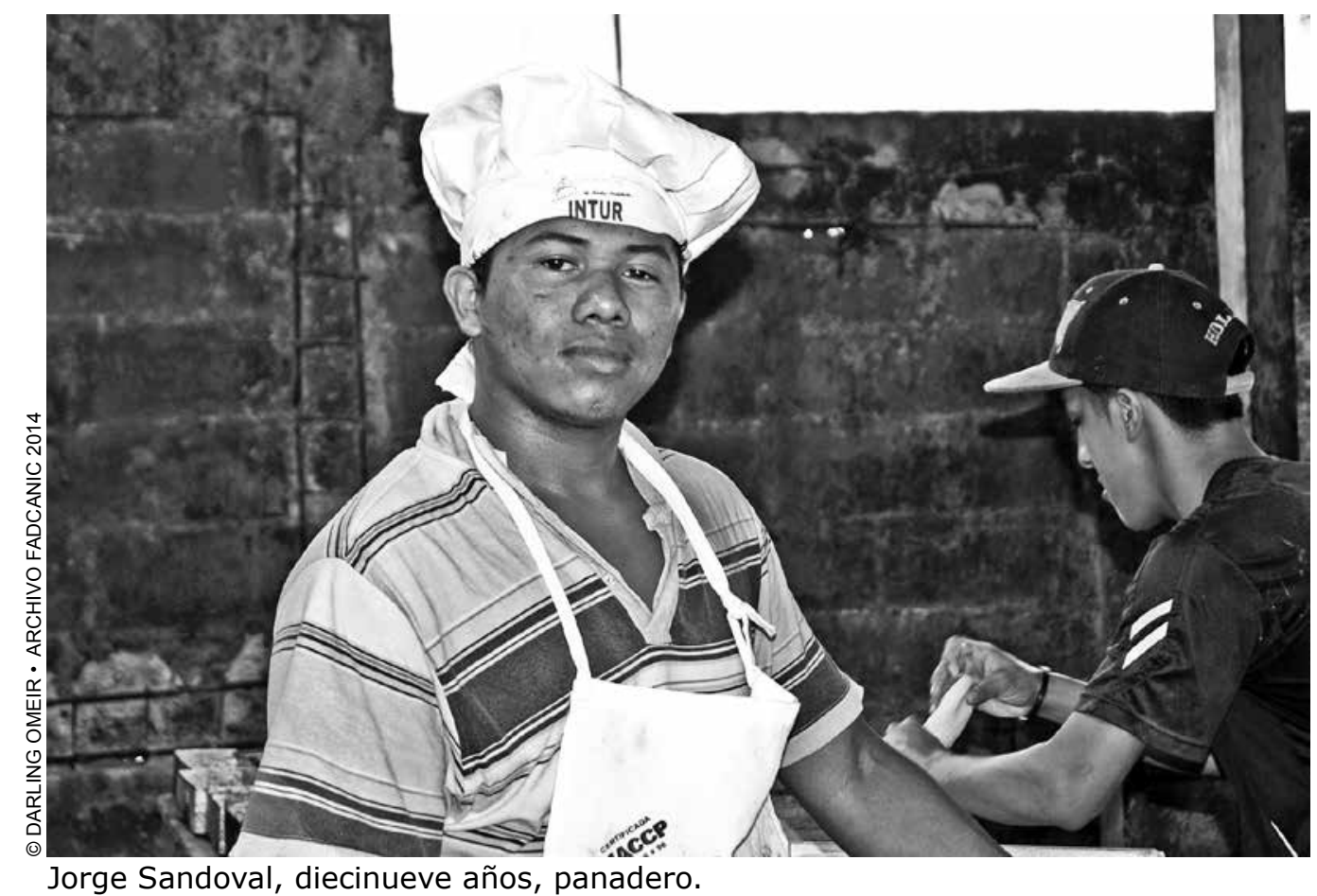


En términos de satisfacción con el ingreso percibido por su trabajo, $57.3 \%$ de las y los jóvenes encuestados refirió encontrarse satisfecho, sin embargo, un sustantivo $41.4 \%$ expresó no estarlo. En esta misma línea, el $44.4 \%$ expresó que el aporte de su primera experiencia laboral fue el dinero que necesitaba; un $35.1 \%$ refirió que la experiencia había sido valiosa para su vida y el trabajo; y un $11.1 \%$ expresó que su primer empleo significó una oportunidad para independizarse.

Desde las percepciones y valoraciones citadas, es posible observar que la inserción laboral de adolescentes y jóvenes se ve marcada profundamente por las circunstancias que aceleran o motivan el ingreso al campo laboral. Situaciones de privaciones económicas colocan a adolescentes y jóvenes en condiciones de vulnerabilidad y de exclusión laboral, al verse forzados a aceptar puestos de trabajo que posiblemente no estén acordes a su formación, aspiraciones personales o proyectos de vida, limitándose con esto su capacidades de agencia, empoderamiento y la acumulación de capacidades necesarias para optimizar sus potencialidades de desarrollo.

\section{Después del primer empleo, ¿trabajos precarios?}

Del total de adolescentes y jóvenes de la RACS que la ENAJ consultó sobre su situación actual laboral, el 69.3\% indicó que no se encontraba trabajando; de este total, el $74 \%$ argumentó que no lo estaba haciendo para continuar sus estudios, sin embargo, $14.2 \%$ refirió que no siguió laborando porque debía cuidar a un familiar.

Sobre el total de adolescentes y jóvenes en la encuesta, el $26 \%$ indicó que se encontraba trabajando para alguien y un $4.8 \%$ que contaba con un negocio propio.

Las actividades económicas en las cuales se encuentran insertos adolescentes y jóvenes que refirieron trabajar, no presentaron grandes cambios respecto a las actividades económicas del primer empleo. La agricultura y el comercio concentran la fuerza laboral juvenil, seguido por el turismo, servicios técnico-profesionales y servicios domésticos.

En esta línea, la principal ruta de acceso al empleo fue a través de amigos (44.9\%), la familia (26.2\%) y una búsqueda personal directa $(21.5 \%)$; reforzándose los planteamientos sobre la importancia del capital social en la inserción laboral efectiva de adolescentes y jóvenes.

Del total de jóvenes que se encontraba trabajando, solo el $30.8 \%$ cuenta con un contrato laboral; el $49.5 \%$ expresó que su trabajo no le proveía de beneficios laborales. Un 14\% indicó que contaba con seguro social (INSS) y un 12.1\% con seguro del INSS y seguros privados. Esta realidad sobre la naturaleza del empleo en adolescentes y jóvenes, puede indicar el nivel de subempleo que experimentan las juventudes, así como las privaciones de beneficios laborales que les distancian de un trabajo decente y les acercan a condiciones laborales precarias; siendo, en este caso, marcadas principalmente por la carencia de protección social para el trabajador y su familia.

\section{Gráfico 4 • Beneficios laborales provistos por empleadores de adolescentes y jóvenes de 13 a 29 años que trabajan en la RACS (en porcentajes)}

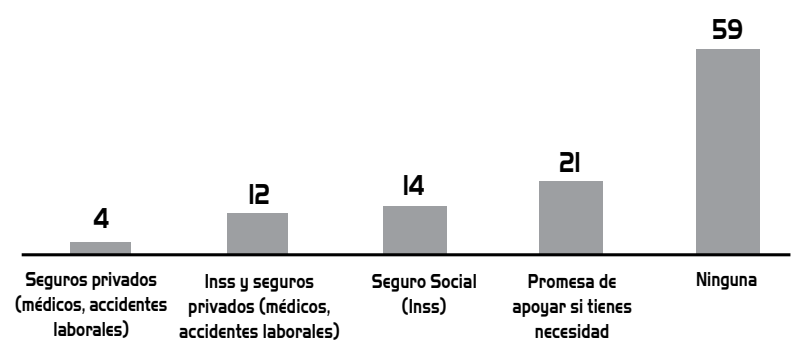

Fuente: Elaboración propia con datos de las Encuesta Nacional de Aspiraciones Juveniles realizada por PNUD en 2009.

A pesar de estas situaciones de informalidad y precariedad laboral, los ingresos percibidos por adolescentes y jóvenes que trabajan se destinan, en gran medida, a la satisfacción de necesidades del hogar. Cerca del $80 \%$ de las y los jóvenes que se encontraban trabajando al momento de la encuesta, expresaron que aportan a su hogar todo lo que ganan, más de la mitad, o la mitad de sus ingresos; siendo posible que dicho aporte refuerce las razones por las cuales adolescentes y jóvenes se mantienen en el ámbito laboral, a pesar de las condiciones poco favorables de sus empleos actuales. (Gráfico 6)

El aporte de la situación laboral actual de adolescentes y jóvenes presenta valoraciones similares a las expresadas sobre el primer empleo. El principal aporte observado en su situación laboral actual es la obtención de un salario $(60.7 \%)$, seguido del valor de la experiencia para la vida y el trabajo (51.4\%), la oportunidad de aprender nuevos oficios y habilidades $(36.4 \%)$ y la oportunidad de independizarse (29.9\%). 
Gráfico 5 • Porcentaje de sus ingresos que aportan adolescentes y jóvenes en la Región Autónoma del Caribe Sur

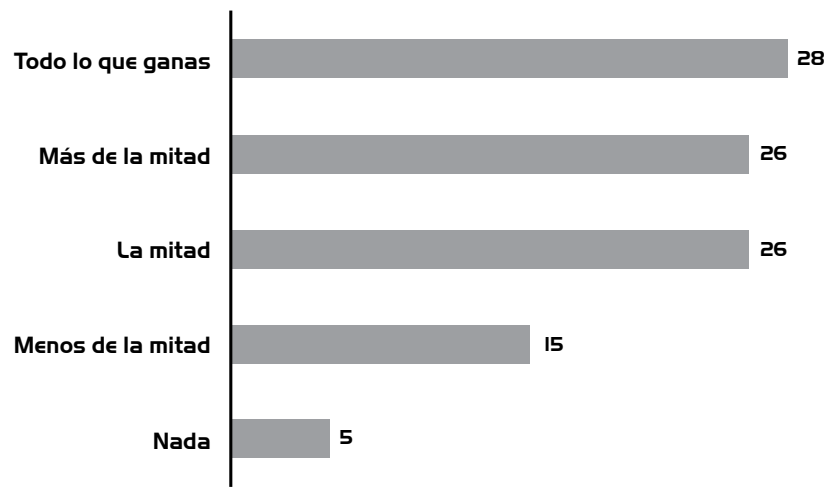

Fuente: Elaboración propia con datos de las Encuesta Nacional de Aspiraciones Juveniles realizada por PNUD en 2009.

Como es posible observar en el Gráfico 6, adolescentes y jóvenes tienden a valorar como muy importantes aquellos aspectos materiales y beneficios concretos, vinculados con la vida laboral que pueden, por un lado, satisfacer necesidades específicas a través de los ingresos derivados de su trabajo, y por otro, posibilitar trayectorias laborales ascendentes a través de la acumulación de experiencia.

En la medida en que los aportes/beneficios del trabajo se alejan de estos ejes, los mismos van perdiendo importancia; es así que, para adolescentes y jóvenes, valores subjetivos vinculados al empleo como mecanismo de cohesión e integración social, como son el reconocimiento social y familiar, son considerados como aportes nada importantes de su situación laboral actual; siendo posible que estas percepciones estén vinculadas con las privaciones que experimentan las juventudes y el rol del empleo en la satisfacción de la misma.

En esta línea, las evaluaciones de los y las mismas adolescentes y jóvenes sobre su trayectoria laboral dan cuenta de las circunstancias que rodean la calidad del empleo que disponen. El $54.3 \%$ de jóvenes que trabajan valora que posee una trayectoria laboral de sobrevivencia, pero acumulando experiencia; contrario a lo señalado por el $34.6 \%$ de jóvenes que considera que tiene una trayectoria laboral ascendente, de desarrollo personal y profesional.

En un escenario de cinco años, estos y estas adolescentes y jóvenes esperan trabajar con un mayor nivel de educación (29.5\%), trabajar con mejores salarios (20.5\%) $\mathrm{y}$ trabajar con mejor calidad (13.6\%). Estas aspiraciones y expectativas positivas están vinculadas con una mayor
Gráfico 6 • Valorización del aporte de su primer trabajo entre adolescentes y jóvenes de la Región Autónoma del Caribe Sur (en porcentaje)

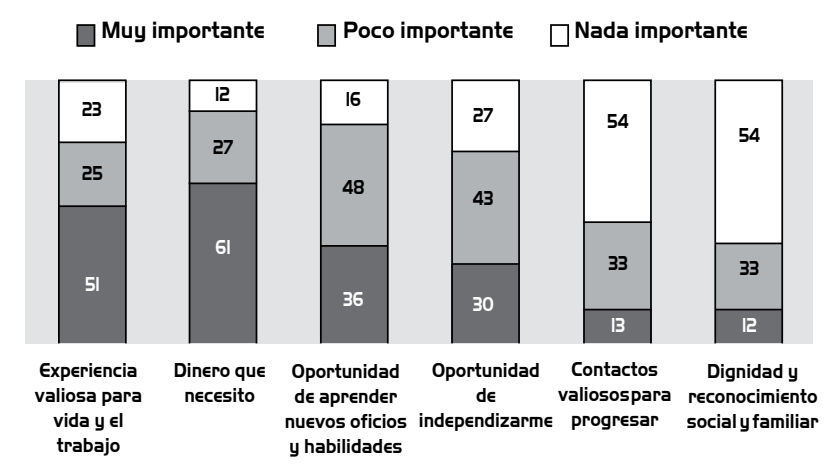

Fuente: Elaboración propia con datos de las Encuesta Nacional de Aspiraciones Juveniles realizada por PNUD en 2009.

formación, una mejor oferta de salarios y puestos de trabajo de calidad.

Pese a la baja calidad de los empleos, los resultados anteriores indican que prevalece una visión optimista respecto al futuro laboral, accediendo a mejores oportunidades profesionales y laborales.

\section{Ni estudian ni trabajan}

Sin embargo, esa visión optimista choca con duras realidades sociales que enfrenta la juventud caribeña. Profundizando en las cifras del EMNV 2009, se revela que tres de cada diez jóvenes entre los quince y diecinueve años de la RACS no estudia ni trabaja (29.7\%), mientras el promedio nacional corresponde al $22.3 \%$. Ese flagelo social resulta más grosero en las mujeres que en los varones, ya que corresponde a $48.9 \%$ versus $9.4 \%$. (Tabla 8 )

Incluso, los indicadores son menos dramáticos en la RACN, donde la cifra de jóvenes entre quince a diecinueve años, que no trabaja ni estudia, corresponde al $19.5 \%$. De ese universo, las mujeres son siempre las más afectadas, ya que aumenta hasta $38.8 \%$.

La situación de los y las jóvenes que no estudian ni trabajan en la RACS, no mejora entre el grupo poblacional de veinte a veinticuatro años; por el contrario se acentúa, ya que $36 \%$ se encuentra en esa situación. Cabe señalar que esa categoría corresponde a jóvenes que: no se matricularon en el sistema educativo, no han recibido cursos o capacitación en los últimos doce meses, y no han trabajado durante la semana pasada o no tienen un trabajo al cual regresar. 


\section{Tabla 8. Porcentaje de Adolescentes de Jóvenes que no trabajan y no estudian en las regiones autónomas, según rango de edad}

\begin{tabular}{lccccccccc}
\hline \multirow{2}{*}{ Rango Edad } & \multicolumn{2}{c}{ Región Autónoma Caribe Norte } & \multicolumn{3}{c}{ Región Autónoma Caribe Sur } & \multicolumn{4}{c}{ Nicaragua } \\
& Hombres & Mujeres & Ambos & Hombres & Mujeres & Ambos & Hombres & Mujeres & Ambos \\
\hline \multirow{2}{*}{$\mathbf{1 5}-\mathbf{1 9}$} & $3,8 \%$ & $38,8 \%$ & $19,5 \%$ & $9,4 \%$ & $48,9 \%$ & $29,7 \%$ & $14,0 \%$ & $31,0 \%$ & $22,3 \%$ \\
$\mathbf{2 0}-\mathbf{2 4}$ & $6,2 \%$ & $54,7 \%$ & $28,0 \%$ & $8,6 \%$ & $64,3 \%$ & $36,0 \%$ & $13,7 \%$ & $45,2 \%$ & $30,0 \%$ \\
TOTAL & $4,7 \%$ & $44,9 \%$ & $22,7 \%$ & $9,1 \%$ & $54,8 \%$ & $32,2 \%$ & $13,9 \%$ & $37,7 \%$ & $25,8 \%$ \\
\hline
\end{tabular}

Fuente: Elaboración propia en base a datos de la Encuesta de Medición de Nivel de Vida 2009 del Instituto Nacional de Información de Desarrollo (INIDE).

Ese universo, del $36 \%$ de jóvenes de la RACS que no estudia ni trabaja, sobrepasa también el promedio nacional del $30 \%$, y del $28 \%$ en la RACN, con. Asimismo, en este grupo etario, el abismo entre mujeres y hombres es gigantesco: $64.3 \%$ versus $8.6 \%$. Eso significa que ese flagelo social afecta ocho veces más a las mujeres que a los hombres de la RACS.

Entre los y las adolescentes y jóvenes, de quince a veinticuatro años, en los cinco municipios donde trabaja el Programa Educación para el Exito, los mayores índices de muchachos y muchachas que no estudian ni trabajan se observan en La Desembocadura de Río Grande (26\%) y en Corn Island (25\%), municipios que sobrepasan el promedio de las cinco localidades (20\%). (Tabla 9)

En el resto de municipios, los resultados son los siguientes: Laguna de Perlas (15\%), Bluefields (17\%) y Kukra Hill $(18 \%)$.

En estos resultados también es visible que este flagelo social afecta más a las mujeres que a los varones, tanto en el rango de edad de quince a diecinueve años, como de veinte a veinticuatro años. En Kukra Hill es más dramático, ya que el $50 \%$ de las jóvenes encuestadas entre los veinte $\mathrm{y}$ veinticuatro años, no estudia ni trabaja.

\section{Inserción laboral juvenil: condiciones y limitantes}

Weller plantea que para lograr una inserción laboral exitosa de las juventudes se requiere de capital humano (educación y capacitación de buena calidad), capital social (relaciones sociales basadas en la confianza, la cooperación y la reciprocidad) y capital cultural (manejo de los códigos establecidos por la cultura dominante). (2007: 76).

Según el mismo autor, (...) para mejorar la inserción laboral de la juventud es necesario establecer un círculo virtuoso entre un contexto más favorable - donde destacan las condiciones macroeconómicas que estimulan el crecimiento económico y por ende la demanda laboral, una nueva institucionalidad del mercado de trabajo y un reforzamiento del capital humano, social y cultural de la juventud-, sobre todo de aquellos en situación de desventaja (Weller, 2007: 81).

Una economía en expansión es condición necesaria para la inserción laboral productiva de la juventud, ya que en economías estancadas, sin un ambiente que estimule nuevas contrataciones, los mejores programas no pueden tener un impacto importante. En un contexto de bajo crecimiento económico, la demanda está limitada incluso para jóvenes que cumplen con las pautas de conocimientos y habilidades requeridas hoy en día por las empresas (Charlín et al., 2006:12).

El mercado laboral juvenil en la RACS se ve altamente influido por las características y dinámicas propias de sus actividades productivas. La carencia de empresas que generen empleos estables y bien remunerados, la alta rotación de los puestos de trabajo, bajos ingresos y puestos de trabajo con baja remuneración que no requieren de una cualificación específica, pueden ser rasgos generales que describan en parte la situación del mercado laboral de las juventudes en la región.

Por otro lado, desde las percepciones de actores claves, las juventudes enfrentan limitantes para lograr una inserción laboral efectiva que potencie sus capacidades $\mathrm{y}$ facilite procesos positivos de inclusión social y construcción de ciudadanía. Si bien las juventudes se encuentran dispuesta a ingresar al ámbito laboral en cualquier tipo de empleo, incluso cuando este implique condiciones de subempleo y precariedad, ven limitada esta disponibilidad por las condiciones económicas y 
Tabla 9. Porcentaje de Adolescentes de Jóvenes que no trabajan y no estudian en cinco municipios de la Región Autónoma del Caribe Sur, según rango de edad

\begin{tabular}{|c|c|c|c|c|c|c|c|c|c|c|c|c|c|c|c|c|c|c|}
\hline \multirow{2}{*}{ Rango Edad } & \multicolumn{3}{|c|}{ Bluefields } & \multicolumn{3}{|c|}{ Corn Island } & \multicolumn{3}{|c|}{ Desembocadura } & \multicolumn{3}{|c|}{ Kukra Hill } & \multicolumn{3}{|c|}{ Laguna de Perlas } & \multicolumn{3}{|c|}{ Total } \\
\hline & H & $M$ & AS & H & $M$ & AS & H & $M$ & AS & H & $M$ & AS & H & $M$ & AS & H & $M$ & AS \\
\hline $15-19$ & $16 \%$ & $16 \%$ & $16 \%$ & $5 \%$ & $26 \%$ & $18 \%$ & $26 \%$ & $32 \%$ & $28 \%$ & $11 \%$ & $13 \%$ & $11 \%$ & $15 \%$ & $14 \%$ & $15 \%$ & 15 & 20 & 17 \\
\hline $20-24$ & $13 \%$ & $21 \%$ & $18 \%$ & $43 \%$ & $25 \%$ & $32 \%$ & $20 \%$ & $25 \%$ & $22 \%$ & $17 \%$ & $50 \%$ & $30 \%$ & $17 \%$ & $13 \%$ & $15 \%$ & $21 \%$ & $25 \%$ & $24 \%$ \\
\hline TOTAL & $15 \%$ & $18 \%$ & $17 \%$ & $23 \%$ & $25 \%$ & $25 \%$ & $23 \%$ & $29 \%$ & $26 \%$ & $13 \%$ & $26 \%$ & $18 \%$ & $16 \%$ & $14 \%$ & $15 \%$ & $17 \%$ & $23 \%$ & $20 \%$ \\
\hline
\end{tabular}

$\mathrm{H}$ : Hombre $\bullet \mathrm{M}$ : Mujer $\bullet$ AS: Ambos Sexos

Fuente: Elaboración propia en base a datos del estudio Vulnerabilidad socioeducativa y económica de adolescentes y jóvenes en cinco municipios de la RACS, elaborado en 2013 por FADCANIC

productivas del contexto, los estereotipos vinculados con el adultismo, las relaciones políticas clientelares, y una desarticulación entre la oferta educativa a nivel técnico y universitario, con los procesos de desarrollo económico y productivo de la región.

En los diferentes grupos focales realizados para el presente estudio, adolescentes y jóvenes compartieron estas limitaciones como factores que generan dificultades para su inserción laboral productiva, incidiendo además en el desarrollo de trayectorias laborales juveniles ascendentes.

Tomando en cuenta estos y otros aspectos descritos anteriormente, el mercado laboral juvenil en la RACS puede describirse como: "poco dinámico", no facilita una inserción productiva de adolescentes y jóvenes a través de trabajos decentes y de calidad, fomenta la precariedad y el subempleo, conduciendo a la sub utilización de la fuerza laboral en los municipios estudiados.

Tabla 12. Factores limitantes para una inserción laboral juvenil efectiva en la Región Autónoma del Caribe Sur

\section{Aspectos estructurales}

Aspectos coyunturales

- La educación ha sido desde el principio de las actividades de la empresa la principal limitación para la inserción de jóvenes al mercado laboral.

- $\quad$ Falta de experiencia, liderazgo y motivación juvenil. satisfactorias.

- Falta de industrialización y organización empresarial para generar nuevos empleo.

- Poca valorización de las carreras técnicas entre la juventud de la región; prefieren el bachillerato.

- A nivel institucional una limitante los constituye el escaso apoyo y coordinación interinstitucional.

- Entre las mujeres jóvenes existe un gran número de embarazos no planificados.

- Falta de seguimiento a programas de formación y capacitación técnica.

- $\quad$ Falta de financiamiento.

- Poca inclusión de las mujeres en los espacios de trabajos no tradicionales en el municipio. 


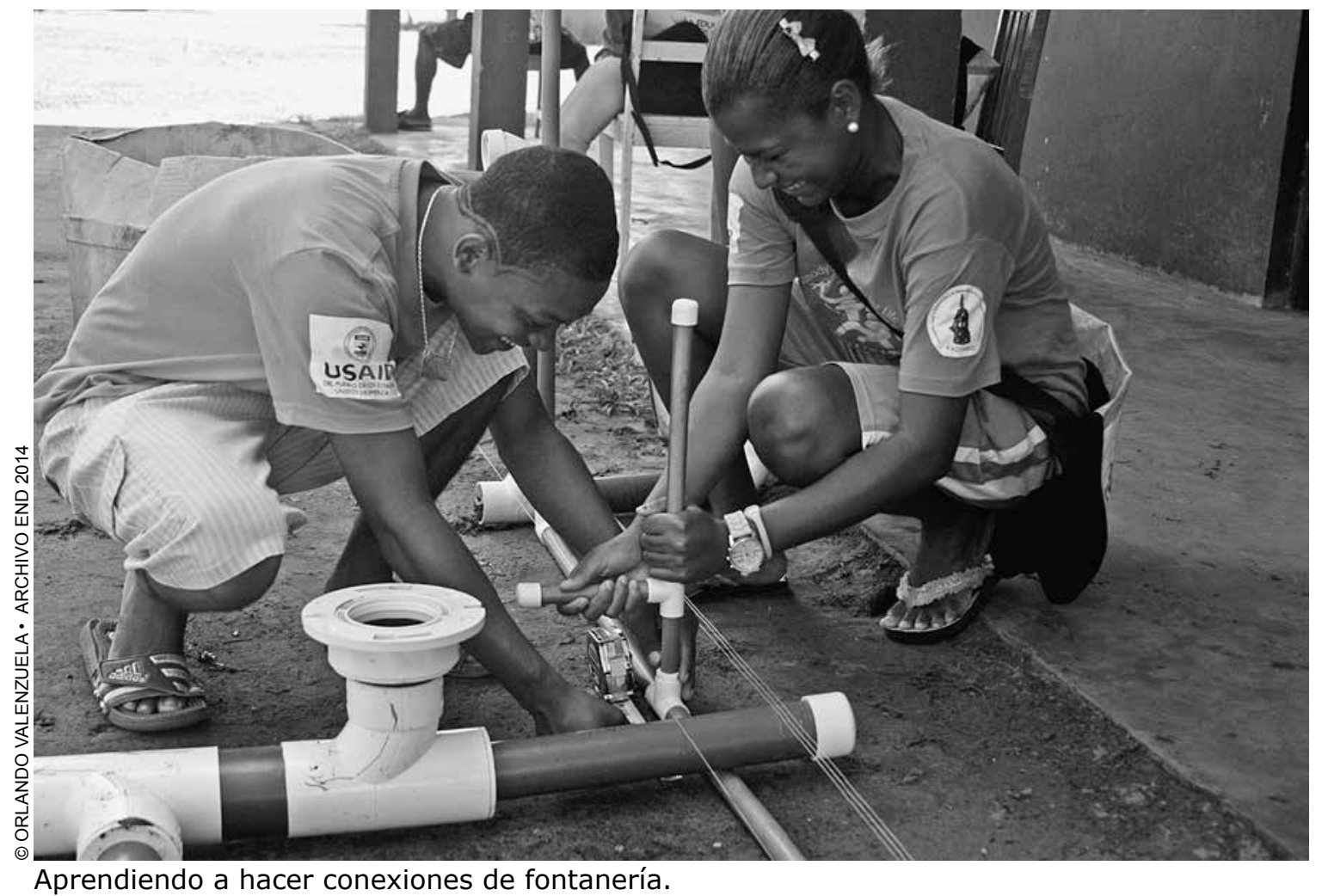

Aprendiendo a hacer conexiones de fontanería.

\section{Recomendaciones}

Qué hacer, cómo intervenir y qué acciones desarrollar para promover mayores oportunidades de inserción laboral en jóvenes que se encuentran en situación de riesgo, demanda una visión multidimensional, una acción intersectorial y multinivel concertada y con metas y propósitos claros y compartidos entre todos los actores involucrados.

Las recomendaciones pueden segmentarse en dos sentidos: primero, de cara a la problemática global del mercado laboral juvenil, es decir, recomendaciones macro que dado su nivel y características, pueden dialogarse y ser implementadas por el conjunto de actores político-institucionales, instituciones de educación, empresa privada y organizaciones de la sociedad civil; segundo, acciones concretas que pueden ser impulsadas por FADCANIC, de cara a optimizar los recursos y condiciones existentes para ampliar las posibilidades de inserción laboral de adolescentes y jóvenes al grupo meta del Programa Educación para el Éxito.

Es importante tener claro que la dinamización del mercado laboral es un proceso complejo. Las condiciones actuales del mismo evidencian desigualdades y exclusiones profundas para adolescentes y jóvenes; y es en ese escenario en el cual se insertan la adolescencia y la juventud en situación de riesgo, lo que complejiza las intervenciones dirigidas a proveer de mayores herramientas para la inserción laboral de los mismos.

El mercado laboral juvenil en su conjunto requiere de:

- Institucionalidad y políticas en juventud y empleo, fortalecidas y con líneas de acción dirigidas a promover el trabajo decente y una inserción laboral efectiva en adolescentes y jóvenes.

- Registro de información y articulación entre sectores educativos y productivos.

- Investigación, innovación y emprendedurismo.

El Programa EduÉxito, por tanto, debe plantearse una ruta de trabajo a partir de las siguientes acciones:

- Realizar coordinaciones con el Ministerio del Trabajo (MITRAB), para el registro de adolescentes y jóvenes en el Servicio Público de Empleo (SEPEM) y ampliar sus posibilidades de inserción laboral a través de los diálogos y posicionamientos que realiza este Ministerio con empresas privadas.

- Coordinar con el componente de MIPYME del MEFCA. 
- Establecer coordinaciones con la Secretaria de Producción, Secretaria de la Juventud, MITRAB, MEFCA, INATEC, BICU y URACCAN, para el diseño de un programa de emprendedurismo juvenil, alineado con las líneas estratégicas del plan de desarrollo de la costa caribe, los sectores productivos priorizados por éste y los potenciales productivos de los municipios de intervención del Programa.

- Desarrollar una estrategia de alianzas con gobiernos municipales, territoriales y comunales y empresas privadas en sectores productivos claves, que facilite la construcción de proyectos conjuntos dirigidos a la promoción del empleo juvenil a través de la combinación entre recursos públicos y privados.

- Fortalecer el proceso de formación vocacional de adolescentes y jóvenes en riesgo, a través de un componente de liderazgo juvenil y valores de empleabilidad, como son la iniciativa personal, responsabilidad, tolerancia y respeto.

- Diseñar un programa curricular articulado con el INATEC a fin de facilitar a la juventud beneficiaria del Programa, posibilidad de continuar especializándose o ampliando sus conocimientos y habilidades técnicas a través de la educación formal.

- Gestionar recursos financieros para el desarrollo de un programa piloto de emprendimiento juvenil, que tome como eje de referencia componentes de formación, financiamiento, seguimiento y acompañamiento de las iniciativas juveniles.

- Promover un intercambio de experiencias con programas similares a EduÉxito o con aquellos que desarrollan un componente de emprendedurismo con jóvenes. Aprender de las experiencias constituye una herramienta fundamental para iniciar acciones en un campo tan complejo como lo es el emprendedurismo juvenil.

Estas recomendaciones persiguen promover procesos escalonados, sostenidos y sistemáticos, que deben de involucrar a un conjunto de actores gubernamentales y del sector privado, para generar mayores oportunidades laborales entre la juventud y aspirar a empleos decentes.

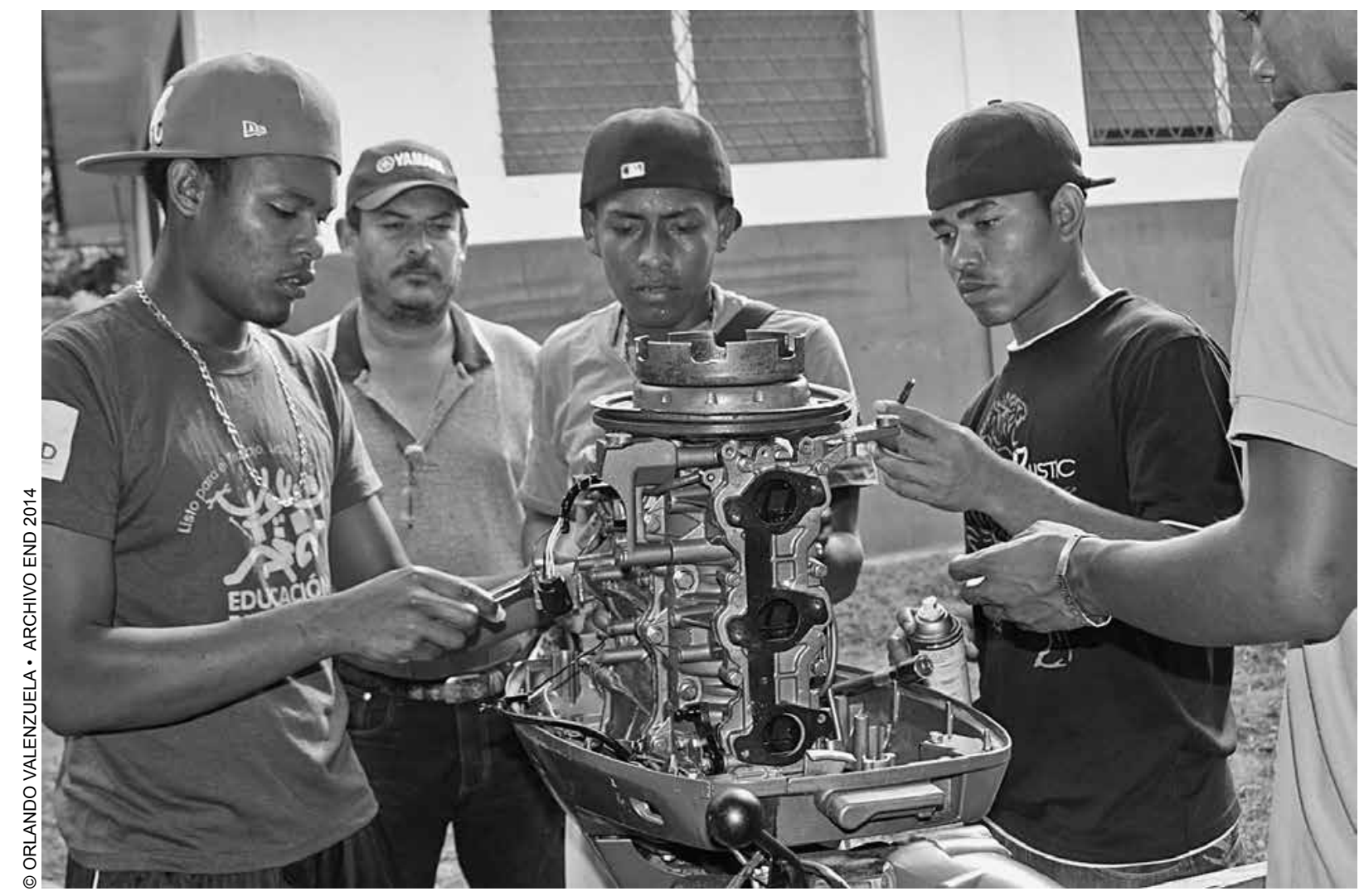

Aprendiendo a reparar motores fuera de borda. 


\section{BIBLIOGRAFÍA}

Bárcena, A. (2008). Juventud y cohesión social en Iberoamérica: un modelo para armar. Naciones Unidas, CEPAL.

Carranza, M. (2006). Oferta, demanda e intermediación laboral: aportes para la integración de jóvenes al mercado de trabajo salvadoreño. CEPAL, Comisión Económica para América Latina y el Caribe.

Centro de Análisis Socio Cultural de la Universidad Centroamericana (CASC-UCA), \& Instituto para el Desarrollo y la Democracia (IPADE). (2004). Encuesta sobre diversidad, pertenencia, identidad y los regímenes de autonomía municipal y regional. IPADE.

Chacaltana Janampa, J. (2006). Empleos para los jóvenes. Lima; Santiago de Chile: CEDEP: GTZ ; CEPAL.

Charlín, M., Weller, J., FLACSO (Organization), Programa Chile, United Nations, Economic Commission for Latin America and the Caribbean, \& Deutsche Gesellschaft für Technische Zusammenarbeit. (2006). Juventud y mercado laboral: brechas y barreras. Santiago: FLACSO-Chile, Facultad Latinoamericana de Ciencias Sociales: Naciones Unidas, Comisión Económica para América Latina y el Caribe.

Gobierno de Reconciliación y Unidad Nacional. (2009). Plan de desarrollo de la Costa Caribe. En ruta hacia el desarrollo humano. Managua.

Gobierno de Reconciliación y Unidad Nacional. (2011). Valoración de la Estrategia de desarrollo de la Costa Caribe y el Alto Wangky Bocay 2007-2011.

Instituto Nicaragüense de Estadísticas y Censos (INEC). (2005, November). XXI. Encuesta de Hogares para la Medición del Empleo Urbano-Rural. Manual del Encuestador.

Programa de las Naciones Unidas para el Desarrollo. (2009). Informe sobre Desarrollo Humano, Honduras 2008/2009 De la exclusión social a la ciudadanía juvenil. Honduras.

Programa de las Naciones Unidas para el Desarrollo. (2010). Informe regional sobre desarrollo humano para América Latina y el Caribe 2010 actuar sobre el futuro: romper la transmisión intergeneracional de la desigualdad. San José, Costa Rica: Programa de las Naciones Unidas para el Desarrollo (PNUD).

Programa de las Naciones Unidas para el Desarrollo (PNUD). (2005). Informe de desarrollo humano 2005: las regiones autónomas de la Costa Caribe; ¿Nicaragua asume su diversidad? Managua: PNUD.

Programa de las Naciones Unidas para el Desarrollo (PNUD). (2011). Informe Nacional Sobre Desarrollo Humano 2011. Las juventudes construyendo Nicaragua. Nicaragua: PNUD.

United Nations, D. P. (2009). Innovar para incluir: jóvenes y desarrollo humano; informe sobre desarrollo humano para Mercosur 2009 - 2010. New York, NY: UNDP. Retrieved from http://hdr.undp.org/en/reports/regional/ latinamericathecaribbean/RHDR_Mercosur_2009 ES.pdf

Weller, J. (2007). “La inserción laboral de los jóvenes: características, tensiones”. Revista de la CEPAL, 92, 62.

Weller, J., United Nations, \& Economic Commission for Latin America and the Caribbean. (2006). Los jóvenes y el empleo en América Latina: desafios y perspectivas ante el nuevo escenario laboral. [Santiago, Chile]; Bogotá, Colombia: CEPAL ; Mayol Ediciones.

Williamson Cuthbert, Dennis. y Fonseca Duarte, Gizaneta (2007). Compendio estadístico de las regiones autónomas de la Costa Caribe de Nicaragua. Managua: Centro de Investigaciones y Documentación de la Costa Atlántica. 


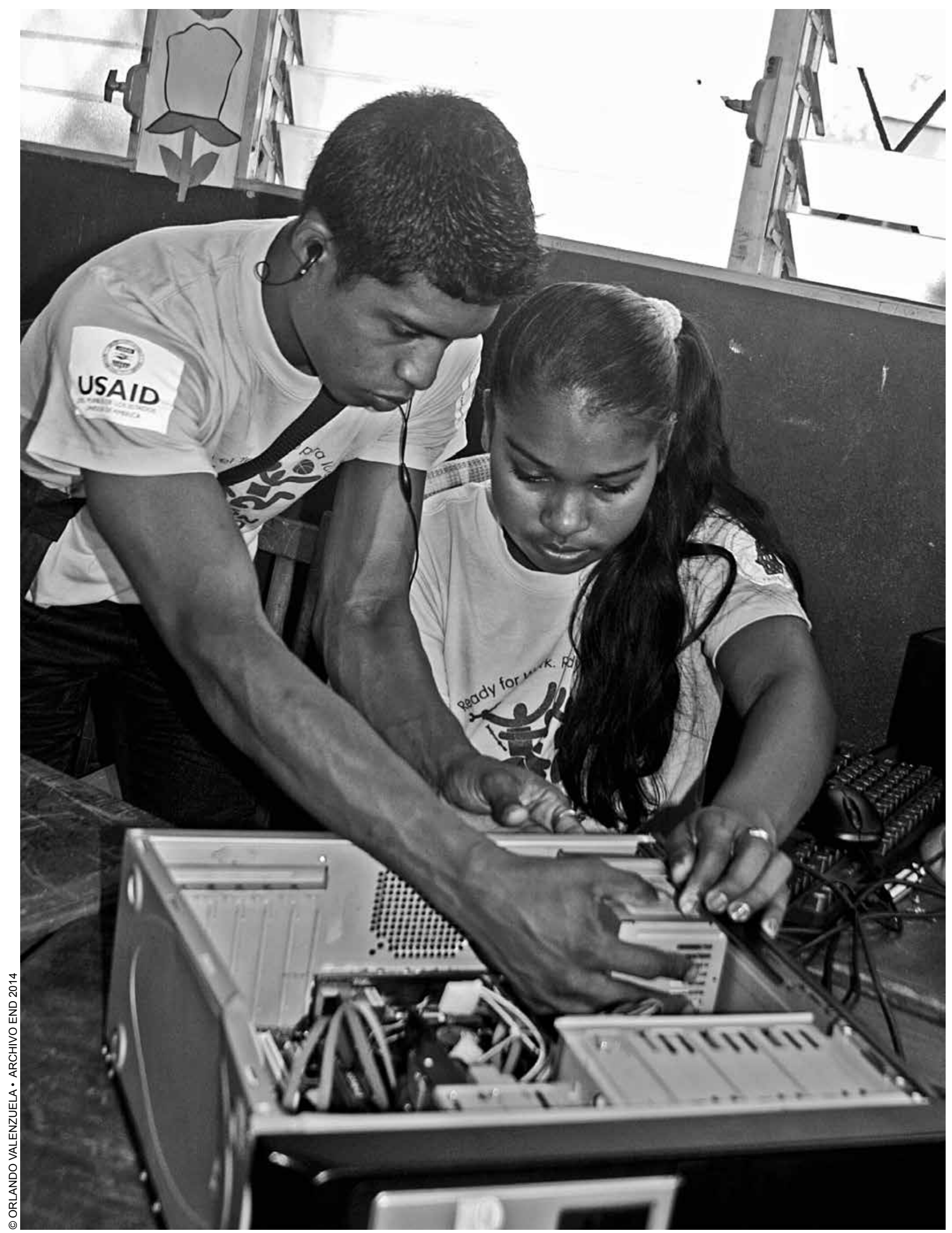

Aprendiendo a reparar computadoras. 